\title{
EXIGÊNCIA DE METIONINA + CISTINA PARA FRANGAS DE REPOSIÇÃO NA FASE INICIAL (1 A 6 SEMANAS DE IDADE)
}

\section{REQUIREMENT OF METHIONINE PLUS CYSTINE FOR PULLETS IN THE INITIAL PHASE (1 TO 6 WEEKS OLD)}

\author{
Priscila D’Agostini ${ }^{1}$ \\ Paulo Cezar Gomes ${ }^{1}$ \\ Heloisa Helena de Carvalho Mello ${ }^{2^{*}}$ \\ Arele Arlindo Calderano ${ }^{1}$ \\ Luciano Moraes Sá ${ }^{1}$ \\ Horacio Santiago Rostagno ${ }^{1}$ \\ Luiz Fernando Teixeira Albino ${ }^{1}$ \\ 1 Universidade Federal de Viçosa, Viçosa, MG, Brasil. \\ 2Universidade Federal de Goiás, Goiânia, GO, Brasil \\ *Autora para correspondência - heloisamello@gmail.com
}

\section{Resumo}

Objetivou-se determinar a exigência de metionina + cistina total para frangas na fase inicial e verificar seu efeito sobre a fase de postura. Na primeira fase experimental, 720 aves (50\% Lohmann LSL e $50 \%$ Lohmann Brown) com uma semana de idade foram distribuídas em delineamento experimental inteiramente casualizado, em esquema fatorial 5 x 2 (níveis de met + cis e linhagens), com quatro repetições e 18 aves por repetição. Os níveis de met + cis total estudados foram 0,$536 ; 0,616 ; 0,696$; 0,776 ; e $0,856 \%$. Ao atingirem 22 semanas de idade, iniciou-se a segunda fase experimental, sendo utilizadas 240 aves (50\% Lohmann LSL e 50\% Lohmann Brown) provenientes da primeira fase experimental. A ração fornecida às aves nesta fase foi igual para todos os tratamentos. Na fase de produção avaliaram-se os efeitos residuais das dietas fornecidas no período inicial sobre os parâmetros produtivos. As exigências de metionina + cistina recomendadas para aves leves e semipesadas, no período de 1 a 6 semanas de idade, são de $0,778 \%$ de met + cis total (correspondendo a $0,700 \%$ de met + cis digestível) e $0,739 \%$ de met + cis total (correspondendo a $0,665 \%$ de met + cis digestível), respectivamente.

Palavras-chave: aminoácidos; maturidade sexual; ovos; poedeiras; requerimentos.

\begin{abstract}
An experiment was carried out to evaluate the requirement of methionine +cystine for growing pullets at starter phase ( 1 to 6 weeks old) and its effect on the laying phase. In the first experiment, 720 birds (50\% Lohmann LSL and 50\% Lohmann Brown) at one week of age were distributed on a completely randomized design, $5 \times 2$ factorial arrangement (levels of met + cys and strain), with four replications
\end{abstract}


and 18 birds each. The levels of total methionine + cystine studied were $0.536 ; 0.616 ; 0.696 ; 0.776$; and $0.856 \%$. At 22 weeks of age, 240 birds were used for the second experimental phase. The diets given to birds at this phase was the same for all the treatments. In the production phase, the residual effects of the experimental diets provided during the initial phase on the production parameters were evaluated. The level of methionine + cystine recommended for white-egg and brown-egg pullets in the period from 1 to 6 weeks of age are $0.778 \%$ of total methionine + cystine $(0.700 \%$ met + cis digestible) and $0.739 \%$ of total methionine + cystine $(0.665 \%$ of digestible methionine + cystine $)$, respectively.

Keywords: amino acids; egg; hens; requeriments; sexual maturity.

Recebido em: 16 janeiro 2013.

Aceito em: 10 fevereiro 2017

\section{Introdução}

Os desenvolvimentos corporal e reprodutivo de aves de postura em crescimento dependem da ingestão em quantidade adequada de nutrientes exigidos para deposição de tecido corporal e formação do aparelho reprodutivo. A maturidade sexual e o desempenho da poedeira estão diretamente relacionados com o sucesso nas fases inicial, cria e recria. Isto ocorre porque os fatores que interferem na idade da ave à maturidade sexual estão diretamente relacionados com o peso corporal e a uniformidade do lote na fase de recria, sendo que existe alta correlação do peso da ave com seis semanas de idade e a idade em que a ave atinge a maturidade sexual. Renema et al. ${ }^{(1)}$ verificaram que o peso do ovário e do oviduto correlaciona-se com o peso corporal da fêmea, evidenciando o efeito do tamanho corporal sobre o desenvolvimento reprodutivo.

O atendimento das exigências dos aminoácidos para as aves de reposição é considerado uma etapa crítica na otimização do desempenho subsequente, sendo afetado por fatores dietéticos, genéticos e ambientais. Portanto, é necessário fornecer, durante esta fase, quantidades de nutrientes que satisfaçam as necessidades de mantença e de ganho, garantindo desenvolvimento adequado dos sistemas imunológico e reprodutivo, empenamento, apetite e estrutura corporal, proporcionando maior produtividade na fase de postura.

As exigências nutricionais de metionina+cistina para aves na fase de produção têm sido avaliadas. De acordo com Saki et al. (2), o aumento do nível de metionina de 0,24 para $0,34 \%$ aumenta a produção de ovos, peso dos ovos, massa de ovos, conteúdo do ovo e consumo de ração e diminui a conversão alimentar. No entanto, as informações disponíveis sobre as exigências nutricionais de metionina + cistina digestíveis de poedeiras comerciais leves e semipesadas na fase inicial são escassas. Além disso, os manuais de linhagens ${ }^{(3-4)}$ não diferenciam as exigências nutricionais de aves leves e semipesadas durante a fase de crescimento. Sabe-se que há diferenças nas exigências nutricionais das aves, de acordo com a linhagem estudada. De acordo com D`Agostini et al. ${ }^{(5)}$, as exigências de metionina + cistina para aves de reposição, leves e semipesadas, no período de sete a doze semanas de idade, foram de $0,639 \%$ de met+cis digestível e $0,635 \%$ de met+cis digestível, respectivamente. Os mesmos autores ${ }^{(6)}$ encontraram exigências de metionina + cistina de $0,611 \%$ de met+cis digestível para aves de reposição leves e de 0,581\% para as semipesadas, no período de 13 a 18 semanas de idade. 
A suplementação de metionina na ração pode ser feita via DL-metionina e metionina hidroxi análoga em ácido livre. Viana et al. ${ }^{(7)}$ verificaram que para frangos de corte essas duas fontes de metionina são equivalentes. Carvalho et al. ${ }^{(8)}$ encontraram biodisponibilidade média de $73,22 \%$ da metionina hidroxi análoga em ácido livre em relação à DL-metionina para poedeiras leves na fase de produção. Independente da fonte de metionina utilizada, é necessário o conhecimento da exigência nutricional da ave para correta suplementação na ração.

Sendo assim, objetivou-se determinar a exigência em aminoácidos sulfurosos para frangas de reposição leves e semipesadas, na fase de 1 a 6 semanas de idade (inicial), bem como avaliar seu efeito durante a fase de produção (22 a 33 semanas de idade).

\section{Material e Métodos}

Um experimento foi realizado no Setor de Avicultura do Departamento de Zootecnia da Universidade Federal de Viçosa, com o objetivo de determinar a exigência de metionina + cistina de frangas de 1 a 6 semanas de idade das linhagens comerciais Lohmann LSL e Lohmann Brown e verificar seu efeito sobre a fase de postura.

A primeira etapa experimental foi realizada na fase inicial (uma a seis semanas de idade) e a segunda etapa na fase de postura ( 22 a 33 semanas de idade).

$\mathrm{Na}$ fase inicial, foram utilizadas 720 aves de reposição fêmeas, sendo 360 aves leves da marca comercial Lohmann LSL e 360 aves semipesadas da marca comercial Lohmann Brown com uma semana de idade. As aves foram pesadas e alojadas em boxes telados, contendo lâmpada de aquecimento, cama de maravalha, bebedouro de pressão na primeira semana, posteriormente substituído por nipple, e comedouro tipo bandeja na primeira semana e posteriormente comedouro pendular.

Utilizou-se o delineamento experimental inteiramente casualizado, em esquema fatorial $5 \times 2$, sendo cinco níveis de met + cis e duas linhagens de aves (leves e semipesadas), com quatro repetições por tratamento e dezoito aves por unidade experimental.

Foram fornecidas rações isocalóricas e isoprotéicas, variando apenas os níveis de met + cis. Os níveis de met + cis foram obtidos a partir de uma dieta basal contendo $0,536 \%$ de met + cis (Tabela 1) suplementada com quatro níveis $(0,08 ; 0,16 ; 0,24$; e $0,32 \%)$ de DL-Metionina (99\%) de forma a proporcionar 0,$616 ; 0,696 ; 0,776$ e $0,856 \%$ de met + cis total. As suplementações com DL-metionina foram feitas em substituição ao amido de milho, assegurando que as rações permanecessem isoprotéicas e isoenergéticas. Os demais nutrientes contidos nas rações foram utilizados atendendo às recomendações preconizadas por Rostagno et al. ${ }^{(9)}$.

Água e ração foram fornecidas à vontade. Todas as aves foram debicadas aos 10 dias de idade. Além disso, foi adotado o manejo de vacinação para controle das principais enfermidades presentes nas aves de postura.

A temperatura no galpão foi monitorada três vezes ao dia por meio de três termômetros de máxima e mínima distribuídos ao longo do galpão, posicionados à altura das aves. As médias das temperaturas mínima e máxima foram 21 e $29^{\circ} \mathrm{C}$, respectivamente.

$\mathrm{Na}$ fase inicial (de uma a seis semanas de idade), foram avaliados o ganho de peso, consumo de ração e conversão alimentar. 
Ao final do período experimental as aves foram transferidas para o galpão de recria, onde permaneceram até a $12^{\mathrm{a}}$ semana de idade, e foram posteriormente transferidas para as gaiolas de postura. Na fase de recria (de sete a 18 semanas de idade), as aves receberam todos os cuidados de manejo e sanitário preconizados no manual da linhagem. $\mathrm{O}$ fornecimento de ração foi à vontade, formuladas de acordo com as recomendações de Rostagno et al. ${ }^{(9)}$.

Quando as aves atingiram 22 semanas de idade iniciou-se a segunda etapa experimental, com 120 frangas da marca comercial Lohmann LSL e 120 da marca comercial Lohmann Brown, provenientes do experimento 1. Inicialmente, as aves foram separadas por tratamento (referente ao experimento 1) e, posteriormente, foram pesadas e alojadas nas gaiolas de forma a garantir o peso médio por repetição dentro de cada tratamento.

O delineamento utilizado foi inteiramente casualizado, em esquema fatorial $5 \times 2$, sendo cinco níveis de met + cis e dois tipos de aves (leves e semipesadas) com quatro repetições e seis aves por unidade experimental. A ração fornecida às aves nesta fase foi igual para todos os tratamentos, atendendo às exigências nutricionais das aves, contendo $2800 \mathrm{kcal} / \mathrm{kg} \mathrm{EM}, 16 \%$ de PB, 0,679\% de met + cis digestível, 4,02\% de Ca e 0,377\% de fósforo disponível, segundo as recomendações preconizadas por Rostagno et al. ${ }^{(9)}$.

O programa de luz adotado foi o fornecimento constante de 17 horas de luz durante todo o período experimental. As temperaturas médias de mínimas e máximas no galpão foram respectivamente 14,4 e $28,8^{\circ} \mathrm{C}$.

Tabela 1. Composição percentual da ração e valor nutricional para frangas de reposição leves e semipesadas de uma a seis semanas de idade

\begin{tabular}{|c|c|}
\hline Ingredientes & $\%$ \\
\hline Farelo de Soja & 33,50 \\
\hline Raspa de Mandioca & 32,58 \\
\hline Sorgo & 27,20 \\
\hline Óleo Vegetal & 2,90 \\
\hline Fosfato Bicálcico & 1,85 \\
\hline Calcário & 0,85 \\
\hline Sal & 0,277 \\
\hline Suplemento Vitamínico ${ }^{1}$ & 0,10 \\
\hline Suplemento Mineral ${ }^{2}$ & 0,05 \\
\hline Antioxidante & 0,01 \\
\hline Virginamicina $50 \%$ & 0,02 \\
\hline Cloreto de Colina $60 \%$ & 0,042 \\
\hline Salinomicina $12 \%^{3}$ & 0,05 \\
\hline Amido & 0,571 \\
\hline Total & 100 \\
\hline \multicolumn{2}{|c|}{ Composição } \\
\hline Energia Metabolizável, kcal/ kg & 2.906 \\
\hline Proteina Bruta, $\%$ & 18,36 \\
\hline Metionina + Cistina total , \% & 0,536 \\
\hline Metionina + Cistina digestiveis, $\%$ & 0,47 \\
\hline Lisina, $\%$ & 1,02 \\
\hline Cálcio, \% & 0,946 \\
\hline Fósforo Disponivel, \% & 0,440 \\
\hline \multicolumn{2}{|c|}{1 - Rovimix (Roche) - kg do produto: vit. A - 10.000 .000 UI; vit D3 - 2.000 .000 UI; Vit E - 30.000 UI; Vit B1 - } \\
\hline \multicolumn{2}{|c|}{ 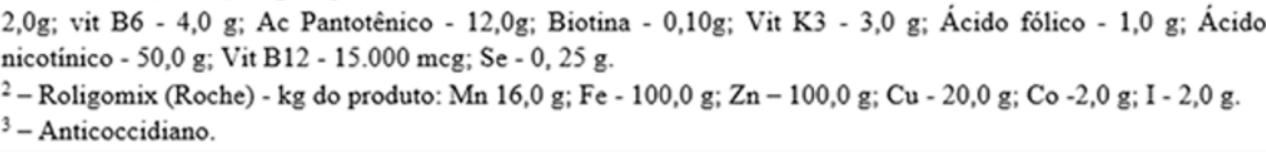 } \\
\hline
\end{tabular}


$\mathrm{Na}$ fase de produção foram avaliados os efeitos dos níveis de met + cis fornecidos no período de uma a seis semanas de idade sobre os parâmetros produtivos. Os parâmetros avaliados foram: a média (em dias) em que as aves atingiram 50\% de produção em cada parcela experimental, produção de ovos, consumo alimentar, conversão alimentar, peso médio dos ovos, peso médio dos componentes dos ovos e Unidade Haugh (UH).

As análises estatísticas foram feitas através de análises de regressão polinomial e "Linear Response Plateau" (LRP), conforme o ajustamento dos dados obtidos para cada variável, utilizando-se o programa SAEG - Sistema para Análises Estatísticas e Genéticas (UFV) ${ }^{(10)}$.

\section{Resultados e Discussão}

Considerando-se os efeitos principais da linhagem de poedeiras, observou-se que as aves semipesadas apresentaram valores superiores de ganho de peso $(23,32 \%)$, de consumo de ração $(3,49 \%)$ e melhor conversão alimentar $(19,46 \%)$ quando comparadas com as aves leves $(\mathrm{P}<0,01)$ (Tabela 2). Estes resultados confirmam que aves semipesadas apresentam de modo geral maior ganho de peso e consumo de ração durante a fase de crescimento quando comparadas com aves leves ${ }^{(3)}$. Rodrigueiro et al. ${ }^{(11)}$ também verificaram efeito da linhagem das frangas de reposição (uma a três semanas de idade) sobre o consumo de ração e conversão alimentar, em que as semipesadas consumiram 4,91\% a mais de ração que as leves e também apresentaram melhor conversão alimentar.

Tabela 2. Parâmetros de desempenho de frangas de reposição leves (L) e semipesadas (SP), no periodo de uma a seis semanas de idade, em função do nível de metionina + cistina nas rações

\begin{tabular}{|c|c|c|c|c|c|c|}
\hline \multirow{3}{*}{$\begin{array}{l}\text { Met + cis } \\
(\%)\end{array}$} & \multicolumn{6}{|c|}{ Parâmetros } \\
\hline & \multicolumn{2}{|c|}{ Ganho de peso (g) } & \multicolumn{2}{|c|}{ Consumo de ração (g) } & \multicolumn{2}{|c|}{ Conversão alimentar } \\
\hline & $\mathbf{L}$ & SP & $\mathbf{L}$ & SP & L & SP \\
\hline 0,536 & 192 & 234 & 878 & 901 & 4,582 & 3,856 \\
\hline 0,616 & 221 & 292 & 899 & 964 & 4,076 & 3,301 \\
\hline 0,696 & 267 & 325 & 968 & 940 & 3,631 & 2,891 \\
\hline 0,776 & 295 & 344 & 929 & 970 & 3,146 & 2,823 \\
\hline 0,856 & 291 & 364 & 913 & 972 & 3,134 & 2,672 \\
\hline \multirow[t]{2}{*}{ Média } & $253^{b}$ & $312^{\mathrm{a}}$ & $917^{b}$ & $949^{\mathrm{a}}$ & $3,714^{\mathrm{a}}$ & $3,109^{b}$ \\
\hline & \multicolumn{4}{|c|}{ Efeito } & & \\
\hline Linear & $*$ & $*$ & ns & $* *$ & $*$ & $*$ \\
\hline Quadrático & $*$ & $*$ & $* *$ & ns & $*$ & $*$ \\
\hline LRP $^{1}$ & $* *$ & $*$ & ns & ns & $*$ & $* *$ \\
\hline Interação & \multicolumn{2}{|c|}{ * } & \multicolumn{2}{|c|}{ ns } & \multicolumn{2}{|c|}{ ** } \\
\hline $\mathrm{CV}(\%)^{2}$ & \multicolumn{2}{|c|}{3,12} & \multicolumn{2}{|c|}{4,23} & \multicolumn{2}{|c|}{4,58} \\
\hline \multicolumn{7}{|c|}{$\begin{array}{l}{ }^{2, b} \text { Letras diferentes na mesma linha diferem estatisticamente pelo teste } \mathrm{F}(\mathrm{P}<0,05) \text {. } \\
{ }^{\prime}(\mathrm{P}<0,01) ;{ }^{* *}(\mathrm{P}<0,05) ; \mathrm{ns}(\mathrm{P}>0,05)\end{array}$} \\
\hline \multicolumn{7}{|c|}{$\begin{array}{l}{ }^{1} \text { Linear Response Platô } \\
{ }^{2} \text { Coeficiente de variação }\end{array}$} \\
\hline
\end{tabular}

Os níveis de met + cis influenciaram significativamente o ganho de peso, o consumo de ração e a conversão alimentar das aves.

Para frangas de reposição leves e semipesadas, o modelo LRP indicou menor soma de quadrados dos 
desvios (SQD) para os valores de todos os parâmetros de desempenho, quando comparada ao modelo de regressão quadrática e linear, indicando melhor ajuste das equações pelo modelo LRP (Tabela 3). O aumento dos níveis de met + cis nas rações causou aumento no ganho de peso das aves leves até o nível de $0,758 \%$ de met + cis, ponto este em que se atingiu o platô, sendo que a partir deste a inclusão de met + cis não aumentou o ganho de peso. Para poedeiras leves, constatou-se efeito quadrático dos níveis de met + cis sobre o consumo de ração.

Tabela 3. Equações de regressão do modelo quadrático e linear, equações linear do modelo linear response platô (LRP) e exigências de met+cis estimadas

\begin{tabular}{|c|c|c|c|c|c|}
\hline Parâmetro & Equação & Platô & Exigência & $\mathbf{R}^{2}$ & SQD $^{1}$ \\
\hline \multicolumn{6}{|c|}{ Leves } \\
\hline \multicolumn{6}{|c|}{ Quadrática } \\
\hline Consumo de ração & $y=-131,31+2964,5 x-2040,7 x^{2}$ & & 0,728 & 0,73 & 0,0013 \\
\hline \multicolumn{6}{|c|}{ LRP } \\
\hline Ganho de Peso & $y=-62,675+469,36 x$ & 293 & 0,758 & 0,98 & 0,0001 \\
\hline Conversão alimentar & $y=7,75751-5,94317 x$ & 3,134 & 0,778 & 0,99 & 0,0007 \\
\hline \multicolumn{6}{|c|}{ Semipesadas } \\
\hline \multicolumn{6}{|c|}{ Quadrática } \\
\hline Conversão alimentar & $y=11,636-21,418 x+12,831 x 2$ & & 0,835 & 0,99 & 0,0108 \\
\hline \multicolumn{6}{|c|}{ Linear } \\
\hline Ganho de Peso & $y=40,5689+389,496 x$ & & 0,856 & 0,94 & 0,0007 \\
\hline Consumo de ração & $y=820,121+185,122 x$ & & 0,856 & 0,22 & 0,0311 \\
\hline \multicolumn{6}{|c|}{ LRP } \\
\hline Ganho de peso & $y=-66,99+569,105 x$ & 354 & 0,739 & 0,98 & 0,0001 \\
\hline Conversão alimentar & $y=7,06571-6,03326 x$ & 2,748 & 0,716 & 0,99 & 0,0034 \\
\hline
\end{tabular}

${ }^{1}$ Soma dos Quadrados dos Desvios

Nas aves semipesadas, verificou-se aumento do ganho de peso à medida que se elevou o nível de met + cis, atingindo-se a exigência ao nível de $0,739 \%$ de met + cis, sendo que a partir deste nível não se verificou aumento do ganho de peso. $\mathrm{O}$ consumo de ração nas aves semipesadas apresentou efeito linear, indicando que os níveis estudados não foram suficientes para determinar o nível máximo de exigência de met + cis para esta variável.

Quando se compara o resultado de ganho de peso e consumo de ração entre as linhagens, verifica-se que aves de reposição leves são mais exigentes em aminoácidos sulfurosos do que as aves semipesadas. Isto pode ser devido ao menor consumo de ração observado nas aves leves nesta fase, exigindo, com isto, níveis mais elevados de met + cis, a fim de suprir as exigências destes aminoácidos e garantir o peso ideal no início da postura.

Foi verificada melhora na conversão alimentar até os níveis de 0,778 e 0,716\% de met + cis, para poedeiras leves e semipesadas, respectivamente, o que indica melhor utilização dos nutrientes da ração, quando se aumentou o nível de suplementação de met + cis. Provavelmente, isto ocorreu devido ao melhor aporte de metionina e cistina em relação aos demais aminoácidos, favorecendo com isto, maior síntese de proteína corporal e melhor aproveitamento de todos os aminoácidos presentes na dieta, visto que metionina é o primeiro aminoácido limitante para aves alimentadas com rações à base de milho e farelo de soja.

Aves leves submetidas à ração com 0,696 e $0,856 \%$ de met + cis atingiram $50 \%$ de produção precocemente, aos 151 dias de idade, em relação àquelas que receberam rações com níveis mais baixos de met + cis. Foi verificado maior atraso na postura nas aves que receberam $0,536 \%$ de met + 
cis, as quais somente atingiram 50\% de produção aos 161 dias de idade.

As aves semipesadas recebendo ração com os níveis superiores a 0,696 \% de met + cis atingiram 50\% de produção aos 149 dias de idade e as aves que receberam os demais níveis atingiram $50 \%$ de produção aos 153 dias de idade.

O fornecimento de níveis de $0,536 \%$ met + cis para aves leves proporcionou atraso na produção de ovos quando comparado aos manuais das linhagens Lohmann LSL e Brown ${ }^{(3-4)}$, que indicam $50 \%$ de produção das aves em média entre 147 e 154 dias de idade. Este atraso se deve provavelmente ao menor peso obtido pelas aves durante não só a fase de uma a seis semanas de idade, como também durante toda sua fase de crescimento, o que ocasionou menor peso durante o início da fase de produção quando comparado aos demais níveis de suplementação de met + cis na ração.

Os resultados obtidos estão de acordo com o proposto por Leeson e Summers ${ }^{(12)}$, que também verificaram que o peso corporal influencia diretamente na maturidade sexual, pois aves que atingiram a maturidade com menor peso corporal, obtiveram maior idade ao primeiro ovo e peso do ovo inferior a aves que chegaram à maturidade mais pesadas. Além disso, diversos autores já afirmaram previamente que a composição do corpo é o fator mais importante que o peso corporal como indicador do preparo do organismo da poedeira para a produção de ovos ${ }^{(13)}$.

No período de postura, verificou-se que aves leves tiveram menor consumo de ração, melhor conversão alimentar por dúzia de ovos e por massa de ovos e maior porcentagem de postura em relação às aves semipesadas (Tabela 4). Desta forma, é possível inferir que as aves leves foram mais eficientes na utilização das rações, bem como na produção de ovos, ou seja, converteram melhor a ração em ovos produzidos.

Tabela 4. Efeitos residuais dos niveis de met + cis na ração de poedeiras leves (L) e semipesadas (SP) no periodo de uma a seis semanas de idade, sobre consumo de ração (CR), conversão por dúzia de ovos (CDO), conversão por massa de ovos (CMO) e porcentagem de ovos produzidos (POP)

\begin{tabular}{|c|c|c|c|c|c|c|c|c|}
\hline \multirow{3}{*}{$\begin{array}{l}\text { Met + cis } \\
(\%)\end{array}$} & \multicolumn{8}{|c|}{ Parâmetros } \\
\hline & \multicolumn{2}{|c|}{ CR } & \multicolumn{2}{|c|}{ CDO } & \multicolumn{2}{|c|}{ CMO } & \multicolumn{2}{|c|}{ POP } \\
\hline & $\mathbf{L}$ & SP & $\mathbf{L}$ & SP & $\mathbf{L}$ & SP & $\mathbf{L}$ & SP \\
\hline 0,536 & 98,4 & 103,8 & 1,30 & 1,35 & 1,75 & 1,89 & 94,2 & 92,4 \\
\hline 0,616 & 99,1 & 103,9 & 1,27 & 1,36 & 1,79 & 1,86 & 93,5 & 91,7 \\
\hline 0,696 & 100,7 & 104,9 & 1,26 & 1,40 & 1,74 & 1,84 & 95,5 & 94,0 \\
\hline 0,776 & 100,1 & 104,1 & 1,26 & 1,40 & 1,70 & 1,89 & 95,2 & 91,1 \\
\hline 0,856 & 101,0 & 102,6 & 1,29 & 1,33 & 1,72 & 1,86 & 96,2 & 92,6 \\
\hline Média & $99,9^{b}$ & $103,9^{\mathrm{a}}$ & $1,28^{b}$ & $1,37^{\mathrm{a}}$ & $1,74^{b}$ & $1,87^{\mathrm{a}}$ & $94,92^{a}$ & $92,36^{b}$ \\
\hline \multicolumn{9}{|c|}{ Efeito } \\
\hline Linear & ns & ns & ns & ns & ns & ns & $* *$ & ns \\
\hline Quadrático & ns & ns & ns & ns & ns & ns & ns & ns \\
\hline $\mathrm{LRP}^{1}$ & ns & ns & ns & ns & ns & ns & ns & ns \\
\hline Interação & \multicolumn{2}{|c|}{ ns } & \multicolumn{2}{|r|}{ ns } & \multicolumn{2}{|c|}{ ns } & \multicolumn{2}{|c|}{ ns } \\
\hline $\mathrm{CV}(\%)^{2}$ & \multicolumn{2}{|c|}{2,465} & \multicolumn{2}{|c|}{4,868} & \multicolumn{2}{|c|}{5,048} & \multicolumn{2}{|c|}{2,423} \\
\hline \multicolumn{9}{|c|}{$\begin{array}{l}\text { Letras diferentes na mesma linha diferem estatisticamente pelo teste } F(P<0,05) \text {. } \\
(P<0,01) ; * *(P<0,05) ; n s(P>0,05)\end{array}$} \\
\hline Coeficiente de & ariação & & & & & & & \\
\hline
\end{tabular}

Não houve efeito significativo $(\mathrm{P}>0,05)$ das dietas fornecidas na fase inicial sobre o consumo de ração e a conversão alimentar na fase de 22 a 33 semanas de idade para ambas as linhagens estudadas. Da mesma forma, 
D`Agostini et al ${ }^{(5)}$ não verificaram efeito residual do fornecimento de diferentes níveis de met + cis na fase de cria (7 a 12) sobre o consumo de ração, a conversão alimentar e a produção de ovos das aves durante a fase de produção.

Observou-se efeito linear dos níveis de met + cis da fase inicial do crescimento sobre a produção de ovos $(\mathrm{P}<0,05)$ das aves leves, indicando que o aumento dos níveis de met + cis na fase de 1 a 6 semanas de idade assegurou maior produção de ovos destas aves na fase de 22 a 33 semanas de idade. Este resultado está acima da estimativa da exigência obtida pela conversão alimentar $(0,778 \%)$ durante a fase de uma a seis semanas. Silva et al. ${ }^{(14)}$ também observaram efeito residual na produção de ovos quando se elevou o nível de lisina na fase de uma a seis semanas de idade. $O$ efeito da suplementação de metionina sobre a produção de ovos de poedeiras comerciais em diversas fases de produção já foi relatado por diversos autores ${ }^{(15-18)}$. Portanto, a suplementação de metionina é tão importante na fase de produção quanto na fase de cria, mantendo um efeito residual sobre a produção de ovos posteriormente na fase de produção.

Quanto às aves semipesadas, as que receberam estes aminoácidos em níveis deficientes, apesar de terem respondido ao aumento do nível de met + cis na fase inicial de criação, tiveram recuperação ao longo do seu desenvolvimento, indicando que, aves com deficiência em met + cis na fase de uma a seis semanas de idade conseguem recuperar nas fases subsequentes de criação, assegurando a formação completa do sistema reprodutivo, tão importante na fase de produção. Este resultado condiz com a hipótese do ganho compensatório observado por Kwakkel et al. ${ }^{(19)}$, em que aves alimentadas à vontade com níveis adequados de lisina nas fases subsequentes à fase inicial não tiveram seu desempenho afetado durante a fase de produção.

Para as aves leves, a porcentagem de albúmen dos ovos aumentou linearmente $(\mathrm{P}<0,05)$ com o aumento dos níveis de met + cis das rações de uma a seis semanas. As demais variáveis utilizadas para avaliar a qualidade interna e externa do ovo não foram influenciadas pelos tratamentos $(\mathrm{P}>0,05)$ (Tabelas 5, 6 e 7).

Independente do nível de met+cis utilizado na fase inicial de criação, as aves semipesadas não tiveram a qualidade interna e externa do ovo afetadas na fase de produção $(\mathrm{P}>0,05)$.

O fornecimento de rações com níveis de met + cis abaixo do estabelecido não afetaram o desempenho futuro da poedeira semipesada. Entretanto, deve-se levar em consideração que a deficiência de met + cis só foi mantida durante a fase de uma a seis semanas de idade e que nas fases subsequentes de criação ( 7 a 12 e 13 a 18 semanas de idade) as aves receberam rações balanceadas de acordo com suas exigências nutricionais.

Tabela 5. Efeitos residuais dos niveis de met + cis na ração de poedeiras leves (L) e semipesadas (SP) no periodo de uma a seis semanas de idade sobre a qualidade dos ovos

\begin{tabular}{|c|c|c|c|c|c|c|}
\hline \multirow{3}{*}{$\begin{array}{l}\text { Met + cis } \\
(\%)\end{array}$} & \multicolumn{6}{|c|}{ Parâmetros } \\
\hline & \multicolumn{2}{|c|}{$\%$ gema } & \multicolumn{2}{|c|}{ \% albúmen } & \multicolumn{2}{|l|}{$\%$ casca } \\
\hline & $\mathbf{L}$ & SP & $\mathbf{L}$ & SP & $\mathbf{L}$ & SP \\
\hline 0,536 & 25,9 & 24,3 & 62,7 & 65,7 & 11,3 & 10,0 \\
\hline 0,616 & 26,1 & 24,6 & 62,6 & 65,1 & 11,3 & 10,3 \\
\hline 0,696 & 25,6 & 24,7 & 63,5 & 65,0 & 10,9 & 10,2 \\
\hline 0,776 & 25,5 & 24,1 & 63,3 & 65,7 & 11,1 & 10,1 \\
\hline 0,856 & 25,1 & 26,0 & 63,9 & 62,8 & 11,0 & 11,1 \\
\hline Média & $25,6^{\mathrm{a}}$ & $24,7^{b}$ & $63,2^{b}$ & $64,9^{a}$ & $11,1^{\mathrm{a}}$ & $10,3^{b}$ \\
\hline \multicolumn{7}{|c|}{ Efeito } \\
\hline Linear & ns & ns & $* *$ & ns & ns & ns \\
\hline Quadrático & ns & ns & ns & ns & ns & ns \\
\hline LRP & ns & ns & ns & ns & ns & ns \\
\hline Interação & \multicolumn{2}{|c|}{ ns } & \multicolumn{2}{|c|}{ ns } & \multicolumn{2}{|c|}{ ns } \\
\hline CV (\%) & \multicolumn{2}{|c|}{4,745} & \multicolumn{2}{|c|}{2,785} & \multicolumn{2}{|c|}{7,616} \\
\hline \multicolumn{7}{|c|}{$\begin{array}{l}\text { a,b Letras diferentes na mesma linha diferem estatisticamente pelo teste } \mathrm{F} \\
\text { LRP - Linear Response Plateau }\end{array}$} \\
\hline
\end{tabular}


Tabela 6. Efeitos residuais dos niveis de met + cis na ração de poedeiras leves (L) e semipesadas (SP) no periodo de uma a seis semanas de idade sobre a qualidade dos ovos

\begin{tabular}{|c|c|c|c|c|c|c|c|c|}
\hline \multirow{3}{*}{$\begin{array}{l}\text { Met + cis } \\
(\%)\end{array}$} & \multicolumn{8}{|c|}{ Parâmetros } \\
\hline & \multicolumn{2}{|c|}{ Peso do ovo } & \multicolumn{2}{|c|}{ Peso da gema } & \multicolumn{2}{|c|}{ Peso do albúmen } & \multicolumn{2}{|c|}{ Peso da casca } \\
\hline & $\mathbf{L}$ & SP & $\mathbf{L}$ & SP & $\mathbf{L}$ & SP & $\mathbf{L}$ & SP \\
\hline 0,536 & 59,8 & 59,6 & 15,5 & 14,5 & 37,5 & 39,2 & 6,77 & 5,95 \\
\hline 0,616 & 59,2 & 61,0 & 15,4 & 15,0 & 37,0 & 39,8 & 6,67 & 6,25 \\
\hline 0,696 & 60,8 & 60,8 & 15,5 & 15,0 & 38,6 & 39,6 & 6,59 & 6,20 \\
\hline 0,776 & 62,0 & 60,4 & 15,8 & 14,6 & 39,2 & 39,7 & 6,88 & 6,10 \\
\hline 0,856 & 61,0 & 59,9 & 15,3 & 15,4 & 39,0 & 37,9 & 6,72 & 6,56 \\
\hline Média & $60,5^{a}$ & $60,3^{a}$ & $15,5^{\mathrm{a}}$ & $14,9^{b}$ & $38,8^{\mathrm{a}}$ & $39,2^{a}$ & $6,73^{\mathrm{a}}$ & $6,21^{b}$ \\
\hline \multicolumn{9}{|c|}{ Efeito } \\
\hline Linear & ns & ns & ns & ns & ns & ns & ns & ns \\
\hline Quadrático & ns & ns & ns & ns & ns & ns & ns & ns \\
\hline LRP & ns & ns & ns & ns & ns & ns & ns & ns \\
\hline Interação & \multicolumn{2}{|c|}{ ns } & \multicolumn{2}{|c|}{ ns } & \multicolumn{2}{|c|}{ ns } & \multicolumn{2}{|c|}{ ns } \\
\hline $\mathrm{CV}(\%)$ & \multicolumn{2}{|c|}{3,160} & \multicolumn{2}{|c|}{3,268} & \multicolumn{2}{|c|}{5,111} & \multicolumn{2}{|c|}{6,688} \\
\hline
\end{tabular}

$\mathrm{a}, \mathrm{b}$ Letras diferentes na mesma linha diferem estatisticamente pelo teste $\mathrm{F}$.

LRP - Linear Response Plateau

$\mathrm{CV}$ - coeficiente de variação

Tabela 7. Efeitos residuais dos niveis de met + cis na ração de poedeiras leves (L) e semipesadas (SP) fornecidos no periodo de uma a seis semanas de idade sobre a Unidade Haugh (UH), Índice de gema (IG) e Índice de albúmen (IA)

\begin{tabular}{|c|c|c|c|c|c|c|}
\hline \multirow{3}{*}{$\begin{array}{l}\text { Met + cis } \\
(\%)\end{array}$} & \multicolumn{6}{|c|}{ Parâmetros } \\
\hline & \multicolumn{2}{|c|}{ UH } & \multicolumn{2}{|c|}{ IG } & \multicolumn{2}{|c|}{ IA } \\
\hline & $\mathbf{L}$ & SP & $\mathbf{L}$ & SP & $\mathbf{L}$ & SP \\
\hline 0,536 & 96,3 & 92,2 & 4,63 & 4,78 & 1,32 & 1,14 \\
\hline 0,616 & 96,8 & 92,3 & 4,62 & 4,73 & 1,32 & 1,15 \\
\hline 0,696 & 97,1 & 92,5 & 4,58 & 4,75 & 1,32 & 1,15 \\
\hline 0,776 & 95,1 & 90,2 & 4,64 & 4,74 & 1,27 & 1,12 \\
\hline 0,856 & 97,0 & 91,6 & 4,62 & 4,71 & 1,33 & 1,11 \\
\hline Média & $96,4^{a}$ & $91,8^{b}$ & $4,62^{b}$ & $4,74^{\mathrm{a}}$ & $1,31^{\mathrm{a}}$ & $1,11^{b}$ \\
\hline \multicolumn{7}{|c|}{ Efeito } \\
\hline Linear & ns & ns & ns & ns & ns & ns \\
\hline Quadrático & ns & ns & ns & ns & ns & ns \\
\hline LRP $^{1}$ & ns & ns & ns & ns & ns & ns \\
\hline Interação & \multicolumn{2}{|c|}{ ns } & \multicolumn{2}{|c|}{ ns } & \multicolumn{2}{|c|}{ ns } \\
\hline $\mathrm{CV}(\%)^{2}$ & \multicolumn{2}{|c|}{2,814} & \multicolumn{2}{|c|}{1,462} & \multicolumn{2}{|c|}{7,168} \\
\hline
\end{tabular}

Observou-se que as aves alimentadas com níveis mais elevados de met + cis durante a fase inicial de criação apresentaram, durante a postura, maior número de ovos com defeito. Provavelmente estes resultados se devem ao maior peso corporal das aves que receberam os maiores níveis de met + cis na ração, o que proporcionou aumento no peso e no número de ovos produzidos, associados à precocidade de início de postura, pois aves que apresentam peso mais elevado no início de produção tendem a apresentar inicio da postura mais precoce, o que leva a uma maior incidência de ovos sem casca, quebrados e de duas gemas.

Os valores estimados de exigência em met + cis totais em frangas de reposição leves, na fase inicial de criação, foram respectivamente 0,758 e $0,778 \%$, para ganho de peso e conversão alimentar. Para 
as aves semipesadas, as exigências em met + cis foram estimadas em 0,739 e 0,716\%, para ganho de peso e conversão alimentar, respectivamente. Considerando a digestibilidade de $90 \%$ para a exigência de met + cis $^{(9)}$, as exigências em met + cis digestíveis para frangas leves de reposição na fase inicial de criação foram estimadas em, respectivamente, 0,682 e 0,700\% para ganho de peso e conversão alimentar e, para semipesadas, em 0,665 e 0,644\% para ganho de peso e conversão alimentar, respectivamente. Logo, a exigência para frangas de reposição leves foi de $0,778 \%$ de met + cis $(0,700 \%$ de met + cis digestível $)$ e para as aves semipesadas foi de $0,739 \%$ de met + cis $(0,665 \%$ de met + cis digestível).

Embora haja a tendência de formulação de rações com base no conceito de aminoácidos digestíveis, Rombola et al. ${ }^{(20)}$ afirmaram que os critérios de formulação de ração (metionina total ou digestível) promovem desempenho semelhante em frangas de reposição na fase inicial e crescimento.

Verificou-se que em $\mathrm{g} / \mathrm{kg}$ as aves leves exigem maior quantidade de aminoácidos sulfurosos em relação às aves semipesadas. No entanto, o consumo em gramas por dia de aminoácidos sulfurosos de poedeiras semipesadas é superior ao das leves, por apresentarem maior consumo de ração do que as poedeiras leves. Deste modo, apesar de as aves semipesadas apresentarem níveis inferiores de aminoácidos sulfurosos por quilo de ração, quando comparados por consumo de ração, verifica-se que as aves semipesadas necessitam de maiores exigências de nutrientes para a mantença e produção. A recomendação de níveis de met+ cis distintos para frangas de reposição leves e semipesadas permite melhor ajuste dos níveis de aminoácidos, evitando com isto a deficiência ou o desperdício de met + cis no metabolismo destas aves. A relação met+cis:lisina total foi de 0,76 para frangas leves e 0,72 para frangas semipesadas. Estas relações são semelhantes à relação recomendada por Rostagno et al. ${ }^{(21)}$ de 0,73 para ambas as linhagens.

\section{Conclusão}

As exigências de metionina + cistina recomendadas para aves de reposição, leves e semipesadas, no período de uma a seis semanas de idade são de $0,778 \%$ de met + cis (correspondendo a $0,700 \%$ de met + cis digestível) e de $0,739 \%$ de met + cis (correspondendo a $0,665 \%$ de met + cis digestível), respectivamente. Ao se considerar a fase de produção (22 a 33 semanas de idade), não se verificou efeito da inclusão de níveis de met + cis na ração, para ambas as linhagens, o que sugere a possibilidade de se utilizarem níveis mais baixos de met + cis na fase inicial de criação, sem afetar a produção e a qualidade dos ovos.

\section{Referências}

1 Renema R, Robinson FE, Proudman JA. Effects of body weight and feed allocation during sexual maturation in broiler breeder hens. 2. ovarian morphology and plasma hormone profiles. Poultry Science, 1999; 78: 629639.

2 Saki AA, Naseri Harsini R, Tabatabaei MM, Zamani P, Haghight M. Estimates of methionine and sulfur amino acid requirements for laying hens using different models. Revista Brasileira Ciência Avícola, 2012; 14 (3): $159-232$ 
3 Lohmann Brown. Manual De Criação E Manejo. Granja Planalto. 10. Ed., 2001, 22p.

4 Lohmann LSL. Manual De Criação E Manejo. Granja Planalto. 10.Ed., 2001 22p.

5 D’Agostini P, Gomes PC, Calderano AA, Mello HHC, Sá LM, Rostagno HS, Albino LFT. Exigência de metionina + cistina para frangas de reposição na fase cria de sete a 12 semanas de idade. Arquivo Brasileiro de Medicina Veterinária e Zootecnia, 2012; 64 (6): 1699-1706.

6 D’Agostini P, Gomes PC, Mello HHC, Calderano AA, Sá LM, Rostagno HS, Albino LFT. Exigência de metionina + cistina para frangas de reposição na fase recria de 13 a 18 semanas de idade. Arquivo Brasileiro de Medicina Veterinária e Zootecnia, 2012; 64 (6): 1691-1698.

7 Viana MTS, Albino LFT, Rostagno HS, Barreto SLT, Carvalho DCO, Gomes PC. Fontes e níveis de metionina em dietas para frangos de corte. Revista Brasileira De Zootecnia, 2009; 38: 1751-1756.

8 Carvalho DCO, Albino LFT, Rostagno HS, Pinheiro SRF, Brito, COM, Viana MTS. Biodisponibilidade de fontes de metionina para poedeiras leves na fase de produção mantidas em ambiente de alta temperatura. Revista Brasileira De Zootecnia, 2009; 38: 2383-2388.

9 Rostagno HS, Albino LFT, Donzele JL, Gomes PC, Oliveira RF, Lopes DC, Ferreira AS, Barreto SLT. Tabelas Brasileiras para Aves e Suínos - Composição de alimentos e exigências nutricionais. $1^{\mathrm{a}}$ Ed. Universidade Federal de Viçosa; 2000. 141p

10 Universidade Federal De Viçosa - Ufv. Sistema De Análises Estatísticas E Genéticas - Saeg. Versão 8.0. Viçosa, Mg, 1999. 142p.

11 Rodrigueiro RJB, Rostagno HS, Albino LFT, Gomes PC, Nunes RV, Neme R. Exigência nutricional de lisina para poedeiras leves e semipesadas nos períodos de 1 a 3 e de 4 a 6 semanas de idade. Revista Brasileira De Zootecnia, 2007; 36 (5):1365-1371.

12 Leeson S, Summers JD. Commercial Poultry Nutrition. 2.Ed. Canada:University Books. 1997. 350p

13 Summers JD, Leeson S, Spratt, D. Rearing Early Maturing Pullets. Poultry Science, 1987, 66: 1750-1757.

14 Silva JHV, Albino LFT Rostagno HS, Gomes PC, Euclydes FR. Exigência de lisina para aves de reposição de 0 a 6 semanas de idade. Revista brasileira de zootecnia, 2000; 29 (6): 1777-1785.

15 Brumano G, Gomes PC, Donzele JL, Rostagno HS, Rocha TC, Mello HHC. Níveis de metionina + cistina digestível para poedeiras leves no período de 42 a 58 semanas de idade. Revista Brasileira De Zootecnia, 2010; 39: 1984-1992.

16 Cupertino ES, Gomes PC, Rostagno HS, Donzele JL, Schmidt M,. Mello, HHC. Exigência nutricional de metionina+cistina digestíveis para galinhas poedeiras de 54 a 70 semanas de idade. Revista Brasileira De Zootecnia, 2009; 38: 1238-1246.

17 Schmidt M, Gomes PC, Rostagno HS, Albino LFT, Nunes RV, Mello HHC. Níveis nutricionais de metionina+cistina digestível para poedeiras leves no segundo ciclo de produção Revista Brasileira De Zootecnia, 2011; 40: 142-147.

18 Polese C, Nunes RV, Vilela CG, Murakami AE, Agustin MAB, Takahashi SE, Vilela VO, Souza C, Schneider S.E. Quantidade de metionina+cistina digestível para poedeiras semipesadas de 75 a 91 semanas de idade. Arquivo Brasileiro de Medicina Veterinária e Zootecnia, 2012; 64: 1682-1690.

19 Kwakkel, RP, Koning FLSM., Verstegen MWA, Hof G. Effect of method and phase of nutrient restriction during rearing on productive performance of light hybrid pullets and hens. British Poultry Science, 1991; 32 (3): 747-761.

20 Rombola LG, Faria, DE., Deponti BJ, Silva FHA, Faria Filho DE, Junqueira OM. Fontes de metionina em rações formuladas com base em aminoácidos totais ou digestíveis para frangas de reposição leves e semipesadas. Revista Brasileira De Zootecnia, 2008; 37 (11): 1990-1995. 
21 Rostagno H S, Albino F L T, Donzele J L, Oliveira R F, Lopes D C, Ferreira A S, Barreto S L T, Euclides R F. Tabelas Brasileiras para Aves e Suínos - Composição de alimentos e exigências nutricionais. $3^{\text {a }}$ Ed. Universidade Federal de Viçosa; 2011. 223p. 